\title{
أسس الثقافة الإجتمـاعية والسيكولوجية في إعداد المواد التعليمية لغير الناطقين بالعربية
}

\author{
Fina Aunul Kafi \\ IAI Al-Falah As-Sunniyyah Kencong Jember \\ (dewakusiwa@gmail.com)
}

\begin{abstract}
In the preparation of Arabic teaching materials for schools need to be adjusted to the socio-cultural and psychological aspects so as to minimize the difficulties of students in understanding the Arabic language lessons presented. Characteristics of good Arabic teaching materials include balanced material between the four competencies and grammar and are adapted to the local conditions of the students. In addition, the relevance of teaching materials is largely influenced by the perception of Arabic teachers on student needs and success in learning. This study aims to discover how the socio-cultural and psychological aspects of preparing Arabic language teaching materials. This research uses descriptive qualitative methods. The results of this study indicate that there is a need for harmony between socio-cultural and psychological aspects with the condition of students to increase success in learning.
\end{abstract}

Keywords: Arabic, psychology, social-culture, teaching material

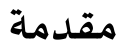

المواد التعليمية هي جميع أشكال المواد المستخدمة لمسـاعدة المعلم في تنفيذ عملية التعلم. يمكن أن تكون المادة المقصودة إما مادة مكتوبة أو غير مكتوبة. تقول آراء الخبراء الآخرين أن المواد التعليمية هي مجموعة من المواد التي يتم ترتيبها بشكل منهـي، مكتوب وغير مكتوب، وذلك لخلق بيئة أوجو يسمح للطاب بالتعلم. 
كان هناك جزء كبير من المواد التعليمية سوف يتسبب الطلاب في صعوبة في استيعاب

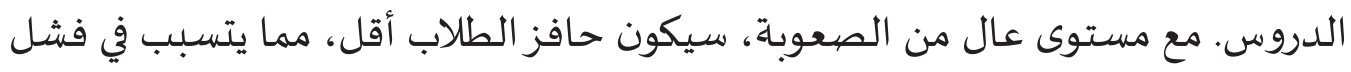

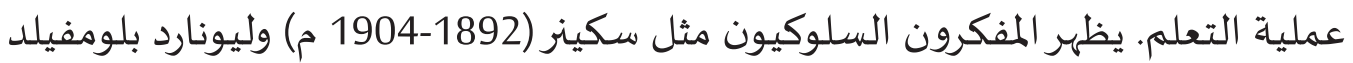
(1887-1949 م) أفضل المواد التعليمية تتوافق مع أسس تعليم اللغة مثل القواعد واللوائح الواضحة. المفردات ، والتعبيرات، وتركيب الجمل ، وما إلى ذلك من عناصر اللغة التي يتم تدريسها والتي تحظى بشعبية أولاً ثم أقل شيوعًا، والمعروفة بالمجهول، وسهلة الصعبة، المهردا،

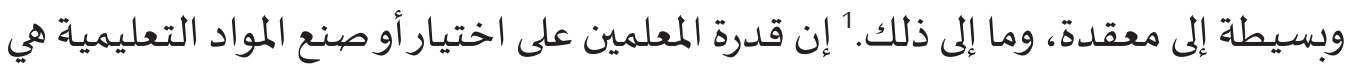
من العوامل المحددة لتنمية قدرات الطلاب كما هومتوقع. يحتاج إلى استعداد المواد التعليمية المدرسون المفهومون في أسس إعداد المواد التعليمياة

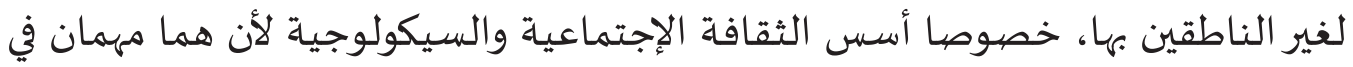
إعداد المواد لتعليم اللغة العربية. ويركز اعداد المواد التعليمياة في أربع مهارات وهي استماع وكلام وقراءة وكتابة.

\section{طريقة البحث}

طريقة البحث التي سيتم استخدامها في هذا البحث هي طريقة نوعياة. وهذا يتفق مع الموضوع محل الدراسـة: اعداد المواد التعليمياة للكتاب العربية. الطريقة النوعية هي طريقة

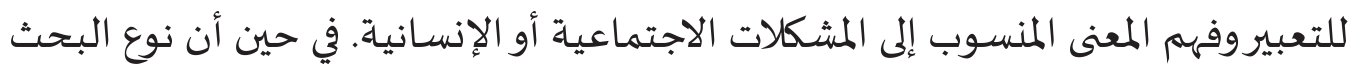

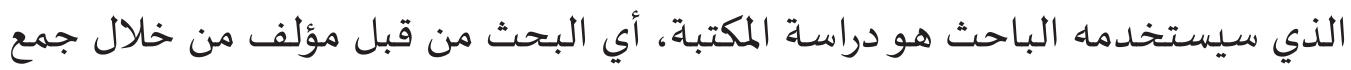
البيانات من الكتب والمجلات واللوائح وبعض الكتابات.

التقنية المستخدمة في هذه الدراسة هي تقنية التوثيق. الوثائق المستخدمة هي في شكل صور أو كتابات أو أعمال لشخص. يتم تنفيذ هذه التقنية من خلال إيجاد المواد ذات الصلة الصلة

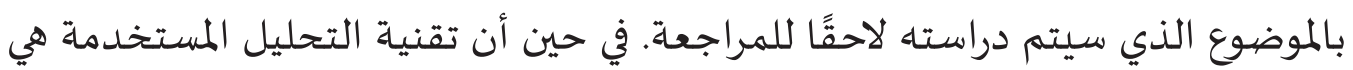
تحليل المحتوى، وهي دراسة منهجية للملاحظات كمصيادربيانات.

'أبراهيم العصيلي. طرائق التدريس اللغة العربية للناطقين بلغة الآخر ارياض: جامعة الإمام محمد بن سعود

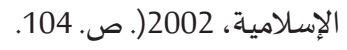


وأما في تصميم البحث، كان أول شيء فعله الباحث في هذه الدراسة هو جمع البيانات

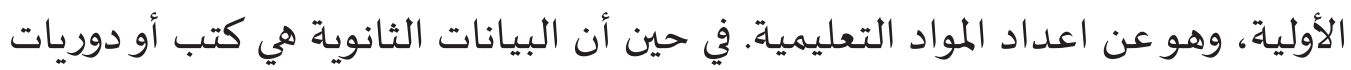
مختلفة تتعلق باعداد المواد التعليمية. من هذه البيانات الأولية والثانوية سيتم تحليلها.

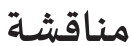

تحتل الثقافة باعتبارها طرائق حياة الشعوب وأنظمتها السياسية والاقتصيادية والاجتماعية والتربوية مكانة مهمة في تعليم وتعلم اللغة، باعتبار أنها محتوى الوعاء اللغوي، وأنها مكون

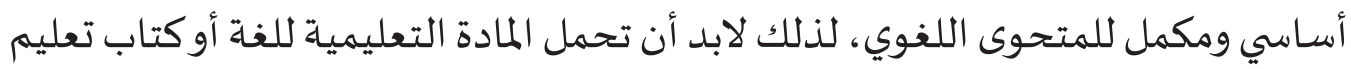
اللغة العناصر الثقافية، بل وينبغي أن تندمج هذه العناصر اندماجاً كلياً في مادة تعليم

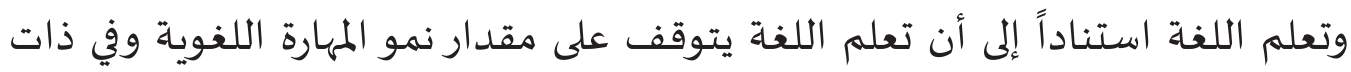
الوقت نمو الحصيلة الثقافية الفكرية.

\section{مفهوم الثقافة الإجتماعية}

عن الثقافة الاجتماعية، أوضح محمود أحمد السيد أن تعليم اللغة يؤدي إلى وظائف

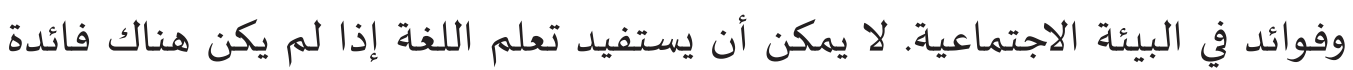

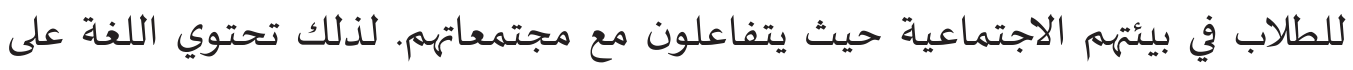

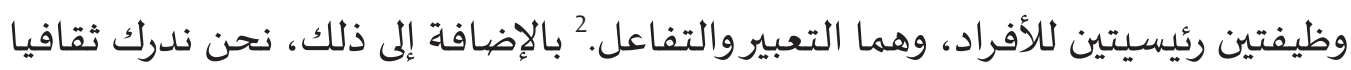

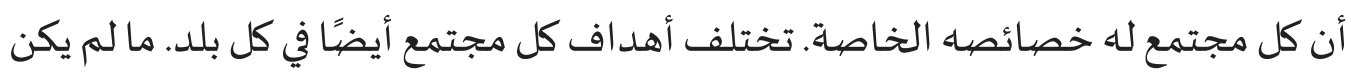
ذلك ممكناً الحد من مجموعة الأهداف التي ينبغي نقلها في تعلم اللغة العربية كلغة ثانية، وخاصة في المجتمعات الإسلامية.

تعرف الثقافة الأفكار والمثل والمعتقدات والمفاهيم والاتجاهات والعادات والتقاليد التي

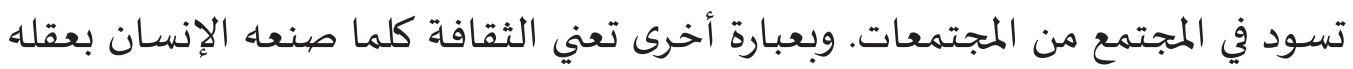

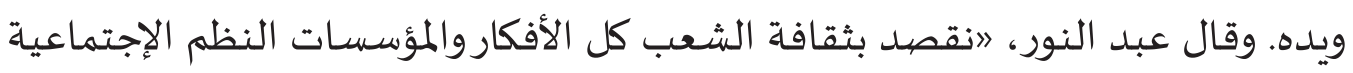
والعادات والتقاليد التي خلقها الإنسان لنفساه، وبدون الثقافة يصبح الإنسان كائنا

r محمود أحمد سيد. في طرائق تدريس اللغة العربية (دمشق: جامعة دمشق، 1997)، ص. 186. 
بيولوجيا فقط يسلك كما كما تسلك الحيوانات».3

فإذا كان الفكرفي الههاية قادراً على أن يعبرعن الثقافة، وأن الثقافة والذات ينتقلان وبشكل رئيسي من خلال الكلمة المقروءة والمكتوبة التي تعبر عن الفكر ، إذن فاللغة وعاء للتفكير

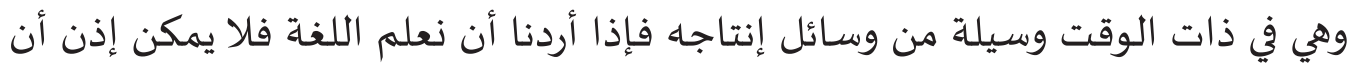

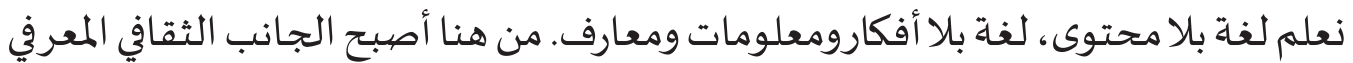
الفكري المعلوماتي جانباً في غاية الأهمية ونحن نعد ونؤلف لتعليم اللغة من حيث اختيار النص اللغوي الذي سنعلم من خلاله اللغة، أي من حيث اختيار المحتوى الفكري الثقافي الذي نتوسل باه ومن خلاله إلى تعليم وتعلم اللغة، فكأنما نقول أناه عند تأليف مواد تعليم اللغة فلابد أن نأخذ في اعتبارنا أن معالجتنا للمحتوى الثقافي لابد أن يتكافأ في الأهمية مع لمعائ

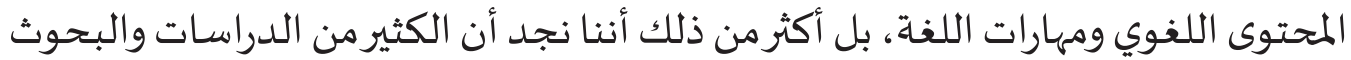
في ميدان تعليم اللغات تكاد تجمع على أن الثقافة والفكروالمعرفة هي الهدف النهائي من أي

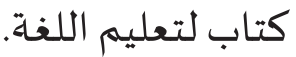

فمن الباحثين من حصرمفهوم الثقافة في الجانب العملى للحياة ـ ذلك الجانب الذى ينتقل من جيل إلى جيل عن طريق التلقين والتبليخ ـ أى أن الثقافة على حد تعبيرهم (هى السلوك الذى ينتقل عن طريق التعلم من جيل إلى جيل) . ومن الباحثين من أطلق الثقافة على الى الثي الجانب النظرى وقصرها على الأمور المعنوية فقال (الثقافة مصطلح يطلق على الجانب الروحى أو الفكرى)، ومن الباحثين من أطلق مصطلح الثقافة على معنويات الأمور ومادياتها، وعلى الجانب النطرى منها وعلى الجانب العملى. دينيا كان أم دنيويا، فقال (تشمل الثقافة ما يتلقاه الفرد عن الجماعة من مظاهر العلوم والفنون والمعارف والفلسفة والعقائد، ويشمل التراث الثقافى أمور معنوية وأخرى مادية ولا تقل إحداهما أهمية عن الأخرى.4 ونقول أنها إذا كان للغة مستويات، فإن للثقافة مستويات، ${ }^{5}$ فلها مستوى حسي ومستوى تجريدي معنوي، ولها مستويات تبدأ بالفرد وتتسع للأسرة ثم للمؤسسات والجماعات. فإنها ينبغي وفي المراحل الأساسية من تعليم اللغة التدرج بمستويات الثقافة

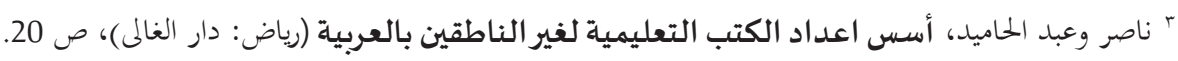

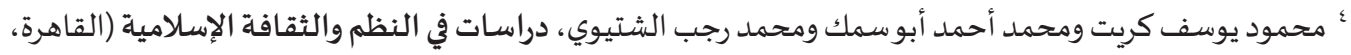

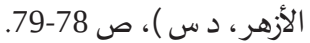
• رشدي أحمد طعيمة، تعليم العربية لغير الناطقين بها (مصر: جامعة المنصورة، 1989م)، ص 217. 
من الحسي إلى المعنوي، ومن الفرد إلى الأسرة إلى المجتمع الأوسع.

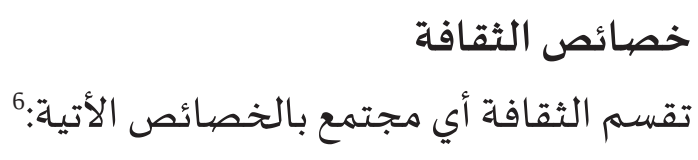

الأول: الثقافة المكتسبة. بمعني أن الإنسان عندما يأني إلى المجتمع من المجتمعات فإنها

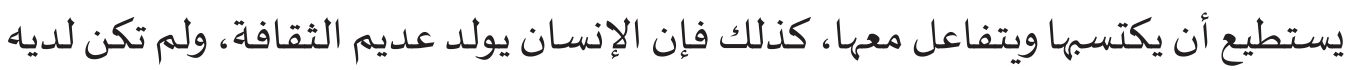

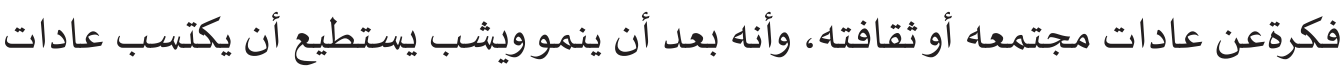
مجتمعاه والتجاهاته وهذا لا يحدد إلا بعد فترة من العيش.

الثاني: الثقافة خاصية إنسانية. امتاز الإنسان عن غيره من سائر المخلوقات بالعقل

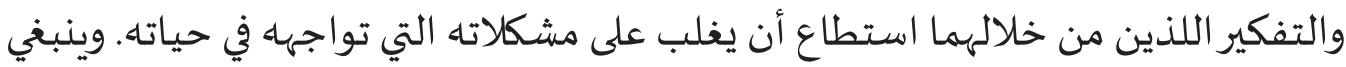

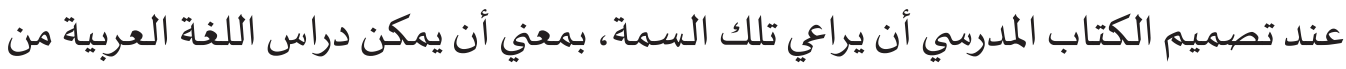

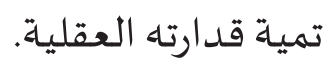

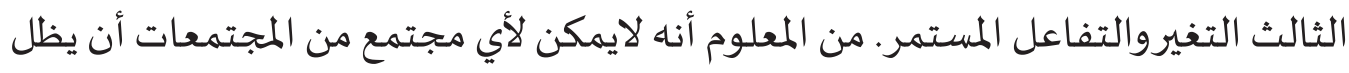

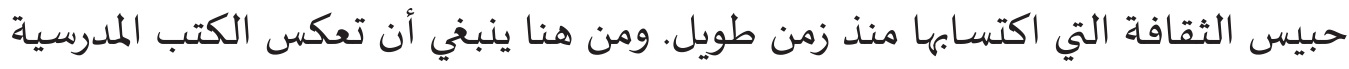
الثقافة العربية وتفاعلها والتغييرات التي تطرأ عليها.

\section{علاقة الثقافة بتعليم اللغة العربية}

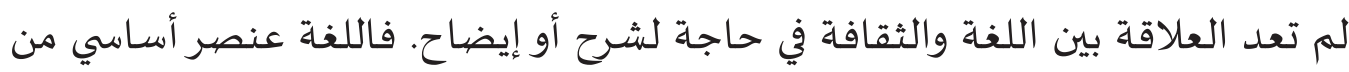

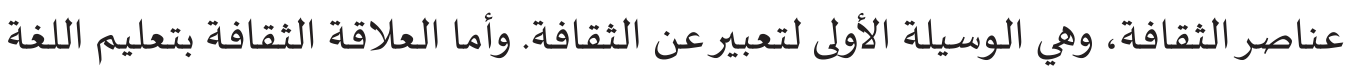
للأجانب، فإن فهم الثقافة المجتمع الإسلامي تعد جزأ أساسيا من تعليم اللغة العربية.

" ناصروعبد الحاميد، أسس اعداد الكتب التعليمية لغير الناطقين بالعربية (رياض: دار الغالى)، ص 22-23.

\begin{tabular}{l|l} 
- Al Fușha : Arabic Language Education Journal \\
Vol. 2 No. 1 Januari 2020 | p-ISSN: 2655-6162 | e-ISSN: 2655-8025
\end{tabular} 


$$
\begin{aligned}
& \text { وهناك موضيوعات يمكن المعلين ليقدمها على الطلاب:7 }
\end{aligned}
$$

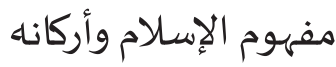

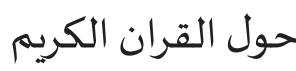

$$
\begin{aligned}
& \text { السنة النبوية }
\end{aligned}
$$

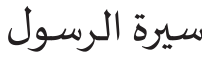

$$
\begin{aligned}
& \text { قصص الأنبياء } \\
& \text { الشريعة الإسلامياة } \\
& \text { العلاقة بين اللغة العربية والإسلام }
\end{aligned}
$$

وعند إعداد كتاب لتعليم اللغة العبية للأجانب فينبغي أن يكون له طابع اجتماعي وثقافي إسلامي، بمعني أنها يخدم لغة العربية وثقافتها ومن خلال مراعتها هي:8

$$
\text { أن يكون محتواه عربيا إسلاميا. }
$$

أن يتضمن المحتوي التعلمي للكتاب عناصر الثقافة العادية والمعنوية بصورة تتناسب

$$
\text { وأغراض الدارسين الأجانب. }
$$

ضرورة الإهتمام بالتراث العربي وخصيائصياء.

انتقاء الثقافة العربية في ضوء حاجة الدارسين واهتمامهم من تعليم اللغة والثقافة. التدرج في تقديم الثقافة من المحسوس إلى المعنوي، من البسيط إلى المركب، ومن الجزء إلى الكلي.

الاهتمام بالثقافة الإسلامية وتوظيفها. مراعة التغييرات الإجتماعياة التي تطرأ علي ثقافتنا. تقديم من العموميات الثقافة العربية وخصوصياتها. إن للدارسين أغراضا من تعلم اللغة والثقافة. تزويد الدراسين بالتجاهات الإسلامية والعلمية.

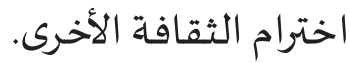

، ناصروعبد الحاميد، أسس اعداد الكتب التعليمية لغير الناطقين بالعربية (رياض: دار الغالى)، ص 25-26.

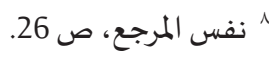




$$
\text { مراعـة تقديم الجانب الثقافة في الكتاب المدرسي. }
$$

مساعدة الدارسين على عملية التطبيع الإجتماعي. لأن القدرة علي التفاعل مع الناطقين باللغة لا تعتمد فقط على إتقان مهارتها بل تعتمد على فهم ثقافة أهل اللغة.

\section{مفهوم أسس السيكولوجيا}

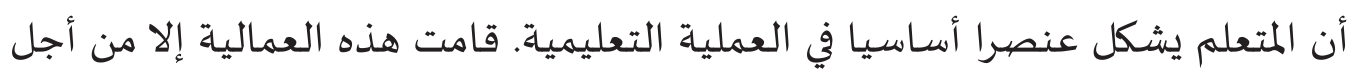

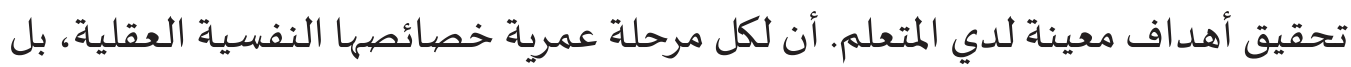
إن الأفراد يختلفون فيما بينهم من قدرات عقلية وسمات نفسية داخل المرحلة العمرية الواحدة.

تعني أسس السيكولوجيا بأنها دوافع التي تدفع المتعلمين لدراسية اللغة العربية لغير

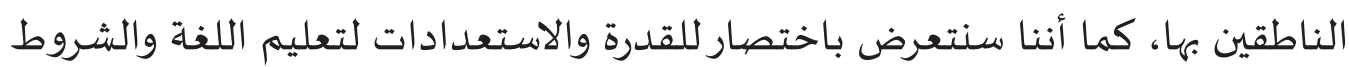
اللازمة عند تصيميم الكتب.

بينما في الجانب النفسي ، أوضح عمر صادق عبد الله أن علماء النفس ينظرون إلى اللغة

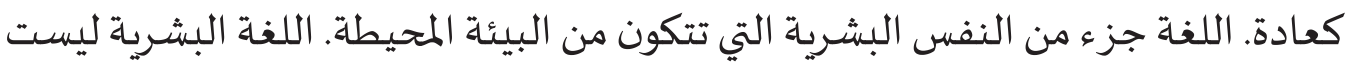

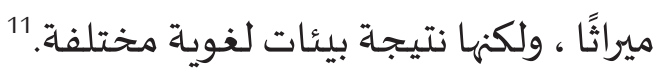
ويهتم علماء النفس والتربية بدراسة المهارة ومكوناتها ونموها كجانب مهم من جوانب التعلم، ولقد التفت المتخصصيون في تعليم اللغات إلى أهمية دراسـة مهارات اللغة وتحليلها عنداء التصدي لوضع المواد التعليمية. ومن الصعب وضع واختيار مواد تعليمياة سليمة ومناسبة

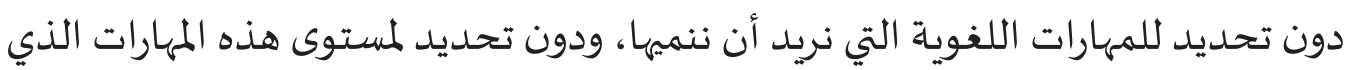
ينبغي أن نبدأ بهاه، والمستوى الذي يجب أت أن ننتهي إليه. إن تحديد مهارات اللغة ومستوياتها المناسبة عادةً ما يقوم على أسـاس مطابقتها بمراحل

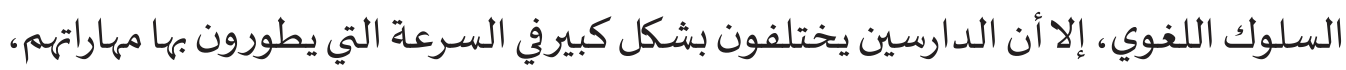
وفي كمية التدريب الذي يحتاجوناه للانتقال والتقدم من مستوى من الكفاءة إلى مستوى

$$
\begin{aligned}
& \text { " نفس المرجع، ص } 28 .
\end{aligned}
$$

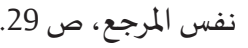

$$
\begin{aligned}
& \text { " عمر صادق عبد الله، تعليم اللغات العربية للناطقين بغيرها (الخرطوم: الدار العامي، 2008)، ص. } 20 .
\end{aligned}
$$


آخر، ومن هنا نجد أن تحديد مستويات عامة للمهارات، أو تحديد تتابع معين لنمو المهارة

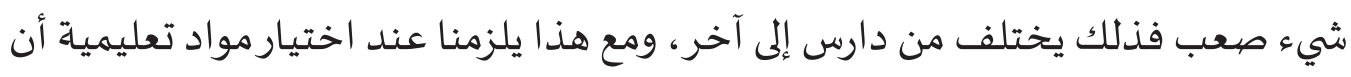
نضع كل هذه الجوانب في اعتبارنا.

ومع الحديث عن الاستعداد يأتي الحديث عن الدوافع والميول، ودورها في تعلم اللغة، فإذا

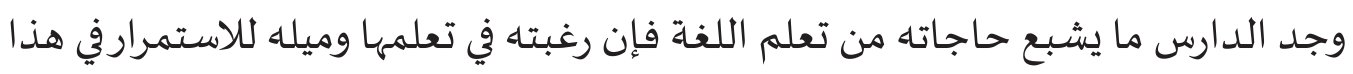
التعلم يتأكدان منذ البداية، ولذلك ينبغي أن تحقق المواد التعليمياة المقدمة إحساساً

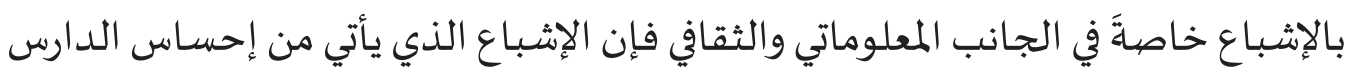

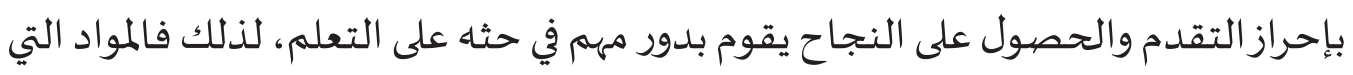

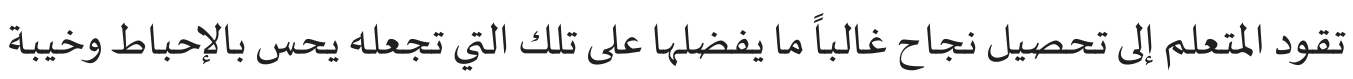
الأمل.

إن الإثارة والدافعية تحدث عندما تستخدم مواد تجعل النجاح في التعلم أمراً ممكناً

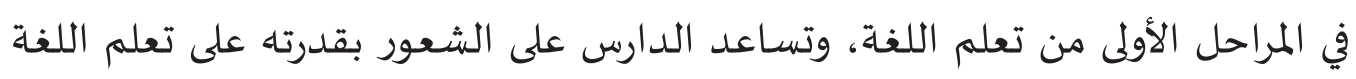

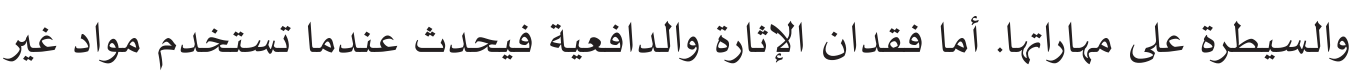

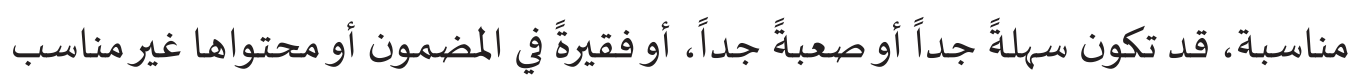
لعمر الدارس وخبراته ومستواه الثقافي.

\section{النفسية وتصيميم الكتاب المدرسي}

من خلال ما تقدم نستطيع أن نستخلص الشروط الأتية:12 أن يكون الكتاب مناسبا لمستوى الدارسين فكريا.

$$
\text { أن يراعى مبدأ الفروق الفردية. }
$$

أن يثيرفي الدارس التفكيرويساعد علي تنميتها بما يساعده على اكتساب اللغة الأجنبية

(العربية)

أن تبني المادة العلمية وفق استعداد الدارسين وقدراتهم. أن يشبع دوافههم ويرضي رغباتهم ويناسب ميولهم.

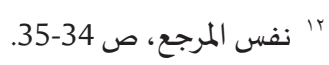


أن يكون الموئف على علم بخصائص الدراسين النفسية. أن يراعى عند التأليف المرحلة العمرية التي يألف لها. أن تؤلف كتب للموهويين في الذكاء، المتوسطى، ومن دونهم.

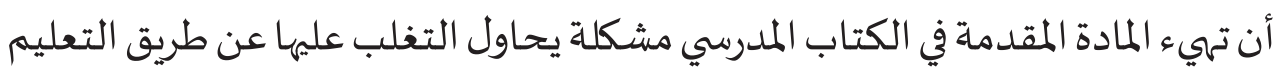

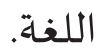

أن تخفز المادة الدارس على استخدام اللغة في مواقفها الطبيعية.

أن يراعي التكامل في المادة بين الكتاب الأساسي ومصاحبته.

أن يقدم مادة علمية من المواقف الحياتية التي تساعد الدارس علي التكيف مع الناطق

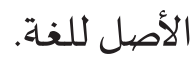

أن يعين الكتاب علي تكرين الاتجاهات والقيم المرغوب فيها لدي الدارسين.

\section{خلاصة}

في هذه المباحثة يعرف بأن تعليم اللغة العربية يختاج على مناسبة بالثقافة والإجتماعية

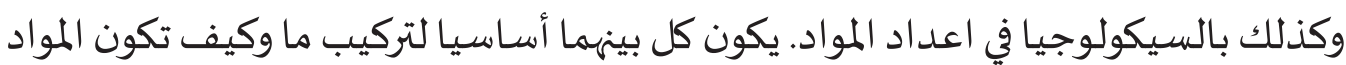

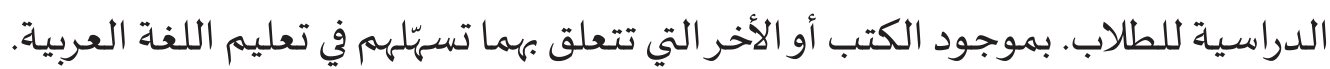
المراد بالثقافة والإجتماعية لأن الإنسان لا يولد كاملا بمفهوماه عن ثقافته واجتماعته، بل

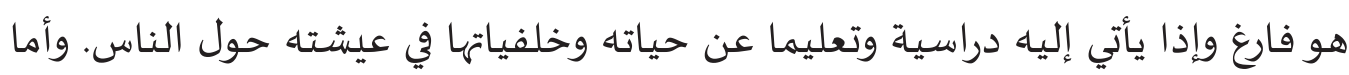

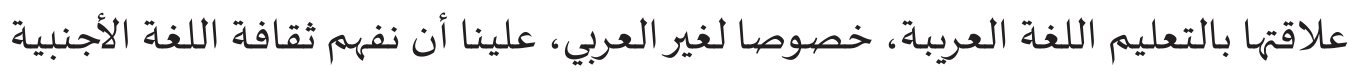

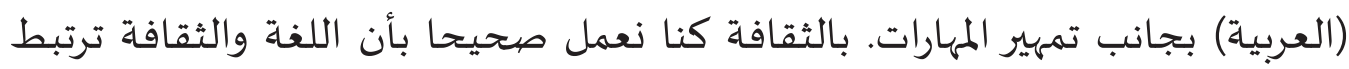

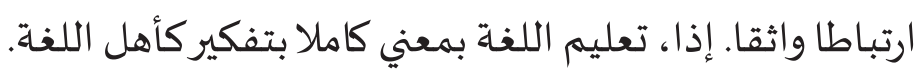

وأما المراد بالسيكولوجيا لأن كل إنسان يختلف بما بينهم من قدرات عقلية وسمات نفسية

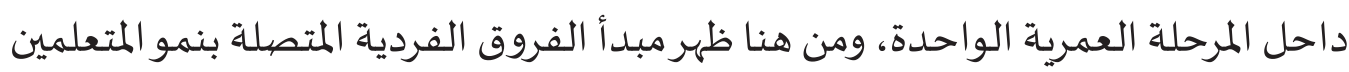

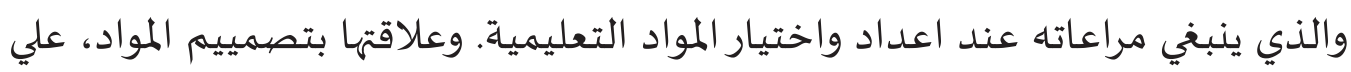

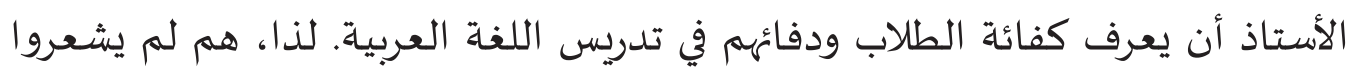

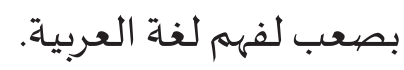




\section{المراجع}

حاميد، ال، ناصر وعبد. د.س. أسس اعداد الكتب التعليمية لغير الناطقين بالعربية.

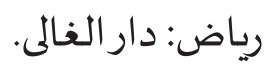

سيد، محمود أحمد. 1997. في طرائق تدريس اللغة العربية. دمشق: جامعاة دمشق.

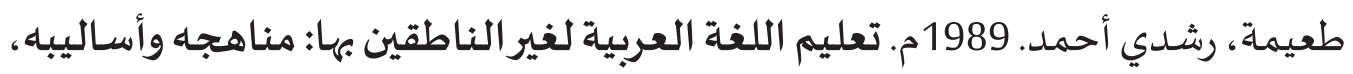
منشورات المنظمة الإسلامية للتربية والعلوم والثقافة-إيسيسكو، الرباط.

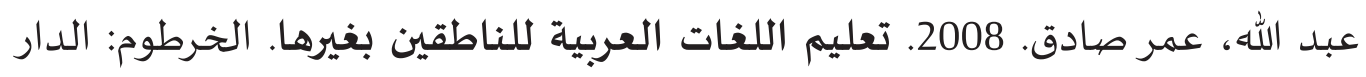

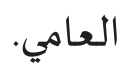
عصيلي، ال، أبراهيم. 2002. طرائق التدريس اللغة العربية للناطقين بلغة الآخر. رياض: جامعة الإمام محمد بن سعود الإسلامية. كريت، محمود يوسف والأخر. د. س. دراسات في النظم والثقافة الإسلامية. القاهرة: الأزهر.

منصور، عبد المجيد سيد أحمد. 1982م. علم اللغة النفسي. الرياض: عمادة شؤون

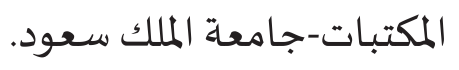

